\title{
Bilateral Basal Ganglia Hemorrhage in a Patient with Confirmed COVID-19
}

\author{
(D) R. Daci, (D) M. Kennelly, (D)A. Ferris, (DM.U. Azeem, (DM.D. Johnson, (D)F. Hamzei-Sichani, (D) A.H. Jun-O'Connell, and
} (iD).K. Natarajan

\section{ABSTRACT}

SUMMARY: Bilateral basal ganglia hemorrhage is exceedingly rare. To our knowledge, our patient is the first reported case of a confirmed coronavirus disease 2019 (COVID-19) patient who had bilateral basal ganglia hemorrhage. In the absence of other risk factors for bilateral deep cerebral involvement, we suspect that COVID-19 may be contributing to these rare pathologies. Most published data represent a correlation between COVID-19 and neurologic complications, and more research is still needed to prove causation.

ABBREVIATIONS: COVID-19 = coronavirus disease 2019; SARS-CoV-2 = Severe Acute Respiratory Syndrome coronavirus 2

C OVID-19 is a highly communicable disease caused by Severe Acute Respiratory Syndrome coronavirus 2 (SARS-CoV-2). The highest viral load for SARS-CoV-2 can be found in the lungs, nasopharynx, and oropharynx, and lower levels are detected in the brain, kidneys, liver, and blood. ${ }^{1}$ Neurologic manifestations may occur in up to $50 \%$ of patients with coronavirus disease 2019 (COVID-19) and may include encephalopathy, anosmia, ageusia, headache, dizziness, seizure, stroke, increased intracranial pressure, SARS-CoV-2 meningitis, and necrotizing encephalitis. ${ }^{2-4}$ There have been cases of ischemic and hemorrhage strokes in patients with COVID-19. ${ }^{5}$ Bilateral basal ganglia hemorrhages per se are exceedingly rare, with 1 study indicating less than 30 reported cases worldwide. ${ }^{6}$ Here we report a case of a patient with COVID-19 who presented with acute, bilateral basal ganglia hemorrhage.

\section{CASE PRESENTATION}

A woman in her 60s with past medical history of obstructive sleep apnea, gastrointestinal reflux, asthma, and migraines presented to our hospital with severe frontal headache, cough, and fatigue. Initial CT of the head was normal (Fig 1, left). Her sputum tested positive for SARS-CoV-2 RNA and she was sent home to quarantine. Two days later, the patient was found unresponsive at her

Received May 29, 2020; accepted after revision June 11.

From the Departments of Neurological Surgery (R.D., M.K., M.D.J., F.H-S., S.K.N.), and Neurology (A.F., M.U.A., A.H.J.-O.), University of Massachusetts Medical School, UMass Memorial Health Care, Worcester, Massachusetts.

Please address correspondence to Sabareesh K. Natarajan, MD, MS, 55 Lake Ave North, Worcester, MA 01655; e-mail: sabareesh.natarajan@umassmemorial.org; @UMassNeuroSurg

- Indicates open access to non-subscribers at www.ajnr.org

http://dx.doi.org/10.3174/ajnr.A6712 home. She was normotensive. A CT of the head revealed bilateral basal ganglia acute parenchymal hematomas with surrounding edema and partial effacement of both lateral ventricles (Fig 1, right). The patient was intubated for airway protection.

CTA and CTV were negative for intracranial aneurysms, vascular malformations, vasospasm, or cerebral venous thrombosis. MR imaging revealed hyperintense lesions on T1, hypointense on T2, high signal on susceptibility-weighted imaging, and no diffusion restriction indicating acute basal ganglia hematomas (Fig 2). MRA and MRV revealed normal flow voids with no evidence of venous occlusion. The carboxyhemoglobin level was 2.7. Ethylene glycol testing was negative. The CSF was not tested for SARS-CoV-2 due to hospital pandemic restrictions. A urine drug screen was positive for prescribed amphetamines and marijuana.

Nine days after admission, the patient was extubated. A CT of the head revealed resolving hematomas. After extubation, the patient remained tachypneic, febrile, and required supplemental oxygen therapy. She developed leukocytosis, thrombocytosis, and lactic acidosis, concerning for either COVID-19 pulmonary manifestations and/or superimposed bacterial infection. Her C-reactive protein was 124.2; erythrocyte sedimentation rate, 99; D-dimer, 2.18; and fibrinogen, 436 . The family decided to initiate comfort measures and the patient died 2 days later due to cardiorespiratory failure.

\section{DISCUSSION}

There have been other reports suggesting involvement of bilateral deep cerebral structures in COVID-19 (Table). There has been 1 previous case reported in the literature of bilateral basal ganglia involvement in a patient with presumed COVID-19 infection; however, that patient's nasopharyngeal SARS-CoV-2 polymerase chain reaction was negative (Table). ${ }^{4}$ Poyiadji et $\mathrm{al}^{7}$ reported a case of a 


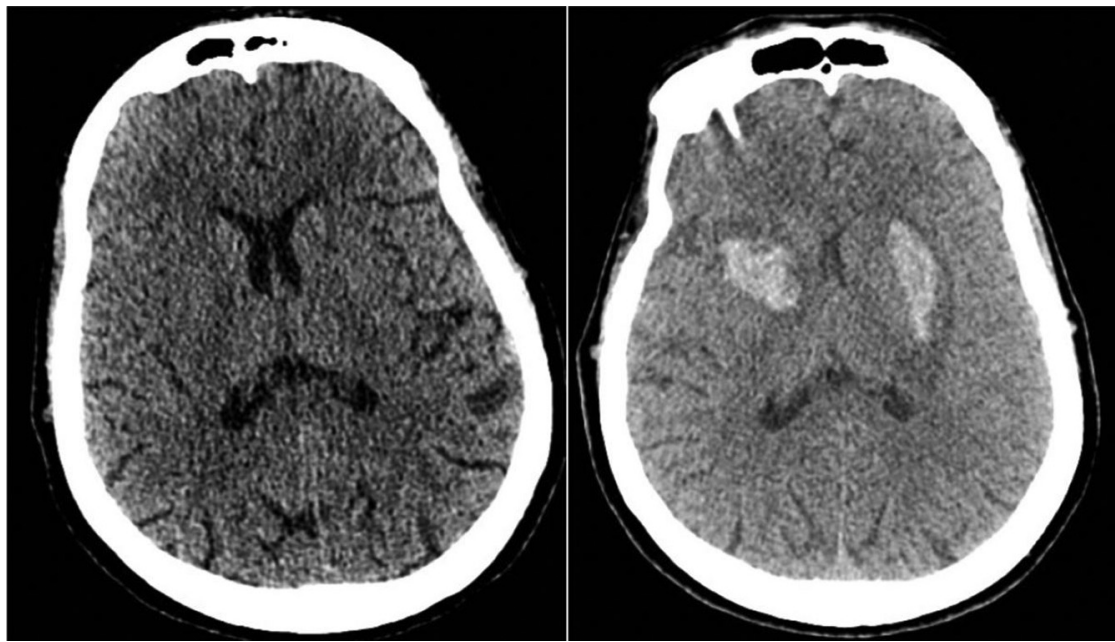

FIG 1. CT of the head obtained on day 1 of presentation (normal head CT, left). Two days later, a CT of the head was obtained because of worsening neurologic status (right). CT of the head revealed bilateral basal ganglia acute parenchymal hematomas measuring $2.7 \mathrm{~cm} \times 1.9 \mathrm{~cm} \times$ $1.4 \mathrm{~cm}$ (right) and $3.8 \mathrm{~cm} \times 1.6 \mathrm{~cm} \times 2.6 \mathrm{~cm}$ (left) with surrounding edema and partial effacement of bilateral lateral ventricles.

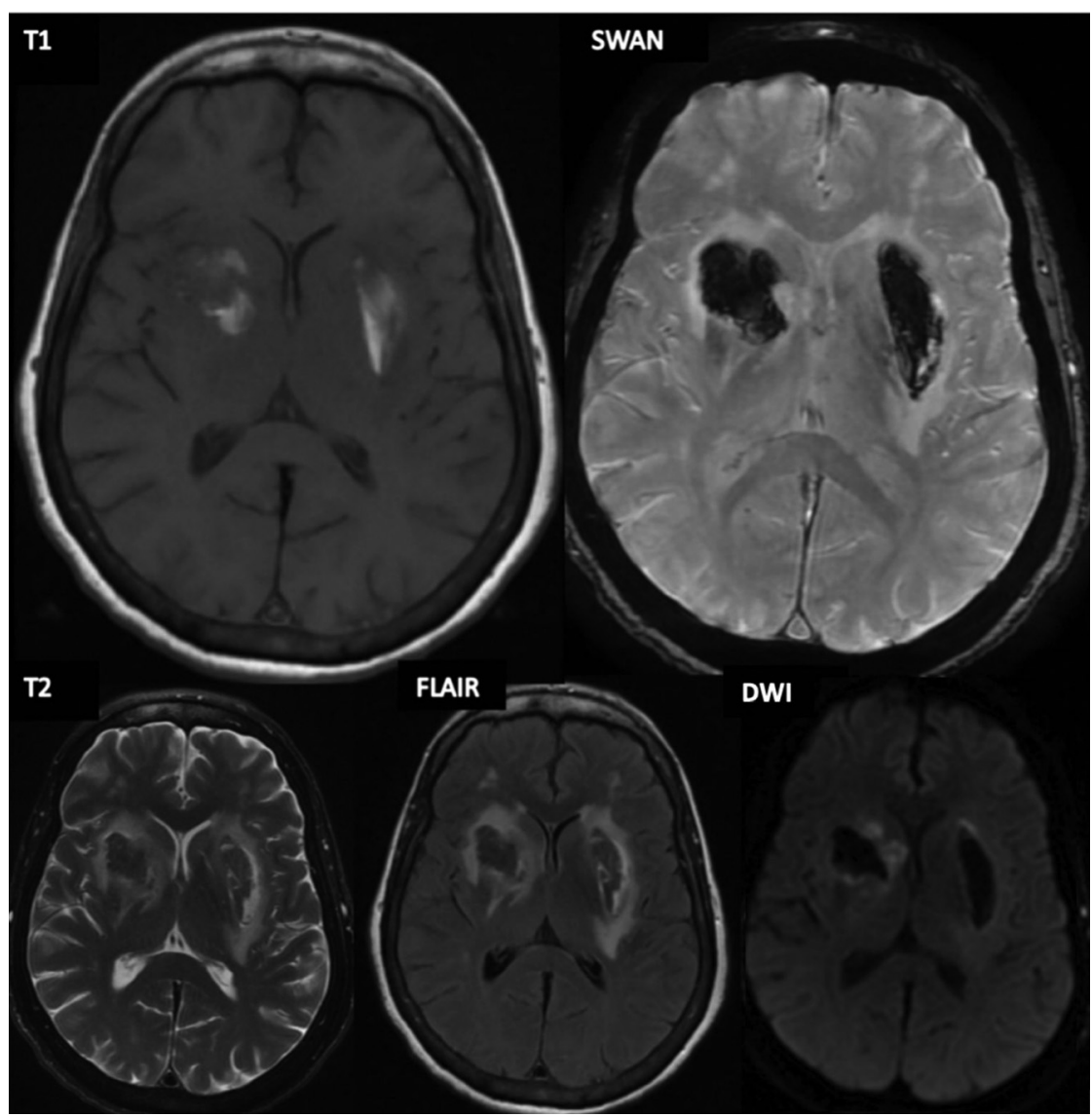

FIG 2. MR imaging of the brain revealing $T 1$ hyperintense lesions (upper right) and high signal intensity on susceptibility-weighted imaging (SWAN, upper left). The lesions are hypointense on T2-weighted images (bottom right), exhibit surrounding edema on FLAIR images (bottom middle), and there is no diffusion restriction (DWI, bottom left). woman with COVID-19 who was found to have hemorrhagic rimenhancing lesions within the bilateral thalami and medial temporal lobes.

The basal ganglia and thalami are highly metabolic brain regions, predisposing them to hypoxic-ischemic injury, toxic poisoning (carbon monoxide, methanol, cyanide), metabolic abnormalities (liver disease, Leigh disease, Wilson disease, hypoglycemia, and osmotic myelinolysis), and neurodegeneration. ${ }^{8}$ Focal flavivirus infection, toxoplasmosis, and primary CNS lymphoma can also attack the bilateral basal ganglia or thalami. ${ }^{8}$ The basal ganglia are supplied by small medial and lateral lenticulostriate arteries of the anterior and middle cerebral arteries, making them susceptible to hypertensive disease. However, basal ganglia hemorrhage in hypertensive disease is unilateral in most cases. ${ }^{6,9}$ Our patient was normotensive on presentation, making hypertensive hemorrhage less likely.

Because the venous drainage of the bilateral basal ganglia is into the great cerebral vein, bilateral basal ganglia hemorrhage could theoretically be explained by great cerebral vein thrombosis. There have been 6 reported cases of cerebral venous thrombosis in patients with COVID-19 in the literature. ${ }^{10}$ Although our patient's MR venogram was negative, it is possible that the patient developed a cerebral venous thrombosis of her galenic venous system and had spontaneous lysis of her clot before imaging.

Traumatic bilateral basal ganglia hemorrhage has rarely been reported. ${ }^{11}$ Although our patient was found unconscious, she did not have any external signs of cranial trauma. Amphetamines in our patient's urine may predispose to ischemia or hemorrhage, however her CTA and MRA were negative for vasospasm. The lesions did not exhibit restricted diffusion, as observed in several hypoxic-ischemic, toxic, or metabolic etiologies. Additionally, testing for carbon monoxide and ethylene glycol was negative.

It has been postulated that SARS-CoV-2 can be neurotropic via the transcribiform route or 


\begin{tabular}{|c|c|c|c|}
\hline & Patient 1 & Patient 2 & Our Patient \\
\hline Age & $50 \mathrm{~s}$ & $50 \mathrm{~s}$ & $60 \mathrm{~s}$ \\
\hline Sex & $\mathrm{F}$ & $\mathrm{F}$ & $\mathrm{F}$ \\
\hline Anatomic location & $\begin{array}{l}\text { Bilateral thalami, bilateral medial } \\
\text { temporal lobes }\end{array}$ & Bilateral basal ganglia & Bilateral basal ganglia \\
\hline $\begin{array}{l}\text { SARS-CoV-2 PCR } \\
\text { nasopharyngeal specimen }\end{array}$ & Positive & Negative & Positive \\
\hline Medical history & Unknown & $\begin{array}{l}\text { Diabetes, hypertension, lumbar } \\
\text { fusion }\end{array}$ & $\begin{array}{l}\text { Obstructive sleep apnea, } \\
\text { gastrointestinal reflux, } \\
\text { asthma, and migraines }\end{array}$ \\
\hline Presenting symptom & Altered mental status & Loss of consciousness & Headache \\
\hline COVID-19 symptoms & Cough, fever & Cough, fever & Cough, sore throat, fatigue \\
\hline Presenting blood pressure & Unknown & $150 / 100$ & $134 / 70$ \\
\hline Chest CT findings & Unknown & Bilateral ground glass opacities & Bilateral ground glass opacities \\
\hline Outcome status & Unknown & $\begin{array}{l}\text { Recovered and discharged from } \\
\text { the hospital }\end{array}$ & Death \\
\hline CSF & Negative for herpes simplex virus & Not obtained & Not obtained \\
\hline
\end{tabular}

Note:-PCR indicates polymerase chain reaction.

the hematogenous circulatory system. ${ }^{2}$ It is unclear why COVID-19 would predispose to bilateral basal ganglia hemorrhage. COVID-19 has been reported to predispose to a hypercoagulable state, increasing the likelihood of cerebrovascular disease and ischemic stroke. ${ }^{12}$ We speculate that the pathology of COVID-19, whether by direct viral invasion or via systemic inflammatory responses, may contribute to bilateral basal ganglia hemorrhage and to other neurologic complications.

Disclosures: Farid Hamzei-Sichani-UNRELATED: Employment: University of Massachusetts Medical School.

\section{REFERENCES}

1. Puelles VG, Lutgehetmann M, Lindenmeyer MT, et al. Multiorgan and renal tropism of SARS-CoV-2. N Engl J Med 2020. [Epub ahead of Print] CrossRef Medline

2. Baig AM, Khaleeq A, Ali U, et al. Evidence of the COVID-19 virus targeting the CNS: tissue distribution, host-virus interaction, and proposed neurotropic mechanisms. ACS Chem Neurosci 2020;11:995-98 CrossRef Medline

3. Asadi-Pooya AA, Simani L. Central nervous system manifestations of COVID-19: a systematic review. J Neurol Sci 2020;413:116832 CrossRef Medline
4. Haddadi KG, Shafizad M. Basal ganglia involvement and altered mental status: a unique neurological manifestation of coronavirus disease 2019. Cureus 2020;12:e7869 CrossRef Medline

5. Tunc A, Unlubas Y, Alemdar M, et al. Coexistence of COVID-19 and acute ischemic stroke report of four cases. J Clin Neurosci 2020;77:227-29 CrossRef Medline

6. Yang Z, Chen J, Mu J. Simultaneous bilateral basal ganglia hemorrhage. Curr Drug Deliv 2017;14:807-15 CrossRef Medline

7. Poyiadji N, Shahin G, Noujaim D, et al. COVID-19-associated acute hemorrhagic necrotizing encephalopathy: CT and MRI features. Radiology 2020;296:e119-20 CrossRef Medline

8. Hegde AN, Mohan S, Lath N, et al. Differential diagnosis for bilateral abnormalities of the basal ganglia and thalamus. Radiographics 2011;31:5-30 CrossRef Medline

9. Zhao J, Chen Z, Wang Z, et al. Simultaneous bilateral hypertensive basal ganglia hemorrhage. Neurol Neurochir Pol 2016;50:275-79 CrossRef Medline

10. Poillon G, Obadia M, Perrin M, et al. Cerebral venous thrombosis associated with COVID-19 infection: causality or coincidence? $J$ Neuroradiol 2020 May 11. [Epub ahead of Print] CrossRef Medline

11. Kankane VK, Gupta TK, Jaiswal G. Traumatic bilateral basal ganglia bleed: a report of rare two cases and review of the literature. Asian J Neurosurg 2016;11:457 CrossRef Medline

12. Goldberg MF, Goldberg MF, Cerejo R, et al. Cerebrovascular disease in COVID-19. AJNR Am J Neuroradiol 2020;41:1170-72 CrossRef Medline 